Gas- f I ow si mul at i on wi th cont act novi ng in GCB consi dering hi gh- pressure and hi gh- temper at ure transport properties of SF6 gas

\begin{tabular}{|l|l|}
\hline 著者 & $\begin{array}{l}\text { Nor i Tadashi, Kawano Hi romi chhi, I wantot o } \\
\text { Kat suhar u, Tanaka Yasunor i , Kaneko Ei j i }\end{array}$ \\
\hline $\begin{array}{l}\text { j our nal or } \\
\text { publ i cat i on t i t l e }\end{array}$ & I EEE Tr ansact i ons on Power Del i very \\
\hline vol une & 20 \\
\hline number & 4 \\
\hline page range & $2466-2472$ \\
\hline year & $2005-10-01$ \\
\hline URL & ht t p: //hdl . handl e. net /2297/1851 \\
\hline
\end{tabular}




\title{
Gas-Flow Simulation With Contact Moving in GCB Considering High-Pressure and High-Temperature Transport Properties of $\mathrm{SF}_{6}$ Gas
}

\author{
Tadashi Mori, Member, IEEE, Hiromichi Kawano, Member, IEEE, Katsuharu Iwamoto, Yasunori Tanaka, and \\ Eiji Kaneko, Member, IEEE
}

\begin{abstract}
This paper addresses a thermal gas-flow simulation in gas circuit-breaker (GCB) chambers, introducing $\mathrm{SF}_{6}$ gas constants up to a pressure of $10 \mathrm{MPa}$ and to a temperature of 30000 $K$. In the simulation, moving parts, such as nozzle, movable arcing contact, and operating rod, are moved with the opening motion of GCB to see if different results are produced from the conventional simulation method, in which fixed parts in the real GCB are moved. As a result, as far as the pressure profile in the puffer chamber is concerned, it is confirmed that this simulation method can produce better results than the conventional method for the hybrid-puffer-type chamber.
\end{abstract}

Index Terms-Gas circuit breakers (GCBs), fluid flow, simulation, dielectric breakdown.

\section{INTRODUCTION}

G AS circuit breakers (GCBs) filled with $\mathrm{SF}_{6}$ gas have been adopted for power transmission systems, especially for high-voltage and high interruption current conditions, due to their novel dielectric and arc extinguishing abilities. Puffer types of $\mathrm{SF}_{6}$ GCBs have been developed up to $550 \mathrm{kV}-63 \mathrm{kA}$ per break. The development of such GCBs has adopted gas-flow simulations [1], [2]. The simulations have been carried out to evaluate temperature, density, and pressure in the arcing area between contacts, as well as the area between enclosed tank and chambers [1], [2]. Such simulations have helped researchers and designers predict the performance of chambers prior to interrupting tests, which saves time and cost of development.

In many gas-flow simulations, the gas property characteristics of $\mathrm{SF}_{6}$ gas have been taken into account. In particular, gas properties, such as gas constant and thermal conductivity, do not indicate linear characteristics against temperature and pressure under high-temperature conditions. Such characteristics were calculated by some researchers [3]-[5] providing gas transport characteristics up to $30000 \mathrm{~K}$ and $1.62 \mathrm{MPa}$ (16 atm in the literature). The data have been practical and have been referred to by many researchers when developing gas-flow simulations

Manuscript received June 29, 2004; revised December 2, 2004. Paper no. TPWRD-00313-2004.

T. Mori, H. Kawano, and K. Iwamoto are with TMT\&D Corporation, Kawasaki 210-0862, Japan (e-mail: morit@ieee.org).

Y. Tanaka is with Kanazawa University, Kanazawa 920-8667, Japan (e-mail: tanaka@ec.t.kanazawa-u.ac.jp).

E. Kaneko is with University of the Ryukyus, Okinawa, Japan (e-mail: kaneko@eee.u-ryukyu.ac.jp).

Digital Object Identifier 10.1109/TPWRD.2005.852360
[6]-[8]. However, the gas pressure in some GCBs is sometimes higher than $1.62 \mathrm{MPa}$, especially in the arc region and its surrounding area. This area is the most important region for gas simulations of GCBs, and data up to $1.62 \mathrm{MPa}$ are sometimes not enough to cover real gas pressure. The authors describe the results of calculations of gas transport characteristics under high temperatures and high pressures up to $10 \mathrm{MPa}$ before gas-flow simulation results.

This paper also discusses which parts should be moved in gas-flow simulations. In many simulations of puffer-type GCBs, stationary arcing contacts are moved [1], [2], [6]-[8], and alternative methods have been applied [9]. These methods can simplify the simulations and make them practical. However, there may be some errors with stationary parts moving under some simulation conditions. The authors evaluated differences between two simulation methods: the movable parts moving method and the stationary parts moving method.

\section{THERMOdYNAMIC AND TRANSPORT PROPERTIES OF $\mathrm{SF}_{6}$ GAS}

Historically, the thermodynamic and transport properties of $\mathrm{SF}_{6}$ gas at a gas pressure below $1.62 \mathrm{MPa}$ were referred to in the literature [4], while the actual pressure in a GCB could reach $5 \mathrm{MPa}$ in our GCBs. Recent circuit breakers (CBs) of the self-blast type feature hot gas, and simulations require more precise and detailed considerations of the thermal properties of the gas. Therefore, the thermodynamic and transport properties of $\mathrm{SF}_{6}$ gas for regions of up to $10 \mathrm{MPa}$ and $30000 \mathrm{~K}$ were obtained and adopted for the simulation in this paper. The outline of calculation methods is as follows. Details can be referred to in the literature [10], [11].

Twenty-three kinds of particles were considered in the calculation, as follows.

$$
\begin{aligned}
& \text { molecules: } \mathrm{SF}_{6}, \mathrm{SF}_{5}, \mathrm{SF}_{4}, \mathrm{SF}_{3}, \mathrm{SF}_{2}, \mathrm{SF}, \mathrm{SSF}_{2}, \mathrm{FSSF} \text {, } \\
& \qquad \mathrm{F}_{2}, \mathrm{~S}_{2} \text {; } \\
& \text { atoms: } \mathrm{F}, \mathrm{S} ; \\
& \text { ions: } \mathrm{F}^{-}, \mathrm{F}^{+}, \mathrm{S}^{+}, \mathrm{F}^{2+}, \mathrm{S}^{2+}, \mathrm{S}^{-}, \mathrm{S}_{2}^{+}, \mathrm{F}_{2}^{+}, \mathrm{SF}^{+}, \mathrm{SF}^{-} \text {; } \\
& \text { electrons: } \mathrm{e}^{-} \text {. }
\end{aligned}
$$

Basic equations relating dissociation and ionise reaction between these particles were solved by the Newton-Raphson method. Fig. 1 shows an example of the equilibrium composition of $\mathrm{SF}_{6}$ gas at a pressure of $2 \mathrm{MPa}$ and a temperature up to $30000 \mathrm{~K}$. 


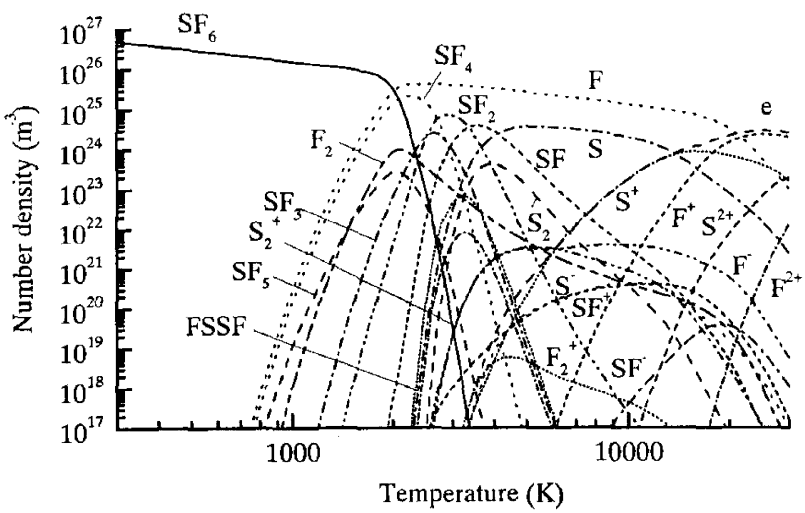

Fig. 1. Equilibrium composition of $\mathrm{SF}_{6}$ plasma at a pressure of $2 \mathrm{MPa}$.

Using the results of gas composition, thermodynamic properties in high temperature $\mathrm{SF}_{6}$ gas with a mixture of the related molecules, atoms, ions, and electrons were obtained.

1) Gas Constant $R$ : Gas constant $R$ is defined as (1) using mass density $\rho$

$$
R=\frac{p}{\rho T}
$$

where mass density $\rho$ can be calculated as (2)

$$
\rho=\sum_{i=1}^{N} m_{i} n_{i}
$$

where $m_{i}$ is the mass of particle $i, n_{i}$ is the density of particle $i$, and $N$ is the number of specimens considered in the calculations.

2) Enthalpy $h$ : Enthalpy $h$ was obtained by (3)

$$
h=\frac{1}{\rho} \sum_{i=1}^{N} h_{i} m_{i} n_{i}
$$

where $h_{i}$ is the enthalpy of particle $i$ and can be obtained by (4)

$$
h_{i}=\frac{1}{m_{i}}\left(\frac{5}{2} k T+k T^{2} \frac{\partial}{\partial T}\left(\ln Z_{i}\right)+\Delta_{f} H_{i}^{0}\right)
$$

where $k$ is Boltzmann's constant, $Z_{i}$ is an internal partition function of particle $i$. In the equation, $\Delta_{f} H_{i}^{0}$ is a standard enthalpy of formation, which is the reaction heat produced from composition elements at a standard state of $0 \mathrm{~K}$ and $0.1 \mathrm{MPa}$.

3) Specific Heat Ratio $\gamma$ : To obtain specific heat ratio $\gamma$, an isopiestic specific heat $C_{p}$ is required

$$
C_{p}=\left.\frac{\partial h}{\partial T}\right|_{p=\text { const }} .
$$

There is the following relationship between isopiestic specific heat $C_{p}$ and specific heat ratio $\gamma$, which enables us to obtain value $\gamma$ :

$$
\gamma=\frac{C_{p}}{C_{v}}=\frac{C_{p}}{C_{p}-R}
$$

The transport properties were calculated using formulas given by Yos, based on first-Chapman-Enskog approximation [12].
4) Electrical Conductivity $\sigma$ : Electrical conductivity $\sigma$ was calculated by (7) and (8)

$$
\begin{aligned}
\sigma & =\frac{e^{2}}{k T} \frac{n_{e}}{\sum_{\substack{j=1 \\
j \neq e}}^{N} n_{j} \Delta_{i j}^{(1)}} \\
\Delta_{i j}^{(1)} & =\frac{8}{3}\left(\frac{2 m_{i} m_{j}}{\pi k T\left(m_{i}+m_{j}\right)}\right)^{\frac{1}{2}} \pi \overline{\Omega_{i j}^{(1,1)}}
\end{aligned}
$$

where $\pi \overline{\Omega_{i j}^{(1,1)}}$ is the momentum transfer collision integral.

5) Thermal Conductivity $\kappa$ : Thermal conductivity $\kappa$ was calculated by the following equations:

$$
\begin{aligned}
\kappa & =\kappa_{\mathrm{tr}}+\kappa_{\mathrm{int}}+\kappa_{\mathrm{re}} \\
\kappa_{\mathrm{tr}} & =\frac{15}{4} k \sum_{i=1}^{N} \frac{n_{i}}{\sum_{j=1}^{N} \alpha_{i j} n_{i} \Delta_{i j}^{(2)}} \\
\alpha_{i j} & =1+\frac{\left(1-\frac{m_{i}}{m_{j}}\right)\left(0.45-2.54 \frac{m_{i}}{m_{j}}\right)}{\left(1+\frac{m_{i}}{m_{j}}\right)^{2}} \\
\Delta_{i j}^{(2)} & =\frac{16}{5}\left(\frac{2 m_{i} m_{j}}{\pi k T\left(m_{i}+m_{j}\right)}\right)^{\frac{1}{2}} \pi \overline{\Omega_{i j}^{(2,2)}} \\
\kappa_{\mathrm{int}} & =k \sum_{i=1}^{N} \frac{\left(\frac{C_{p i} M_{i}}{R_{u n}}-\frac{5}{2}\right) n_{i}}{\sum_{j=1}^{N} n_{j} \Delta_{i j}^{(1)}} \\
\kappa_{\mathrm{re}} & =k \sum_{\ell=1}^{N_{r}} \frac{\left(\frac{\Delta H_{\ell}}{R T}\right)^{2}}{\sum_{i=1}^{N} \frac{\beta_{\ell i}}{n_{i}}\left\{\sum_{j=1}^{N}\left(\beta_{\ell i} n_{j}-\beta_{\ell j} n_{i}\right) \Delta_{i j}^{(1)}\right\}}
\end{aligned}
$$

where $\pi \overline{\Omega_{i j}^{(2,2)}}$ is the viscosity collision integral, $M_{i}$ is the molecular mass of particles $i, R_{u n}$ is the universal gas constant $(=8.31 \mathrm{~J} / \mathrm{mol} \cdot \mathrm{K}), N_{r}$ is the number of chemical reactions, and $\beta_{\ell i}$ is the stoichiometric coefficient in $\ell$ th chemical reaction of particle $i . \Delta H_{\ell}$ is the reaction heat per mol calculated by (15)

$$
\Delta H_{\ell}=\sum_{i=1}^{N} \beta_{\ell i} h_{i} M_{i} .
$$

Figs. 2-6 show the calculation results for gas constant $R$, enthalpy $h$, specific heat ratio $\gamma$, electrical conductivity $\sigma$, and thermal conductivity $\kappa$, respectively. Each figure contains the results for pressures 0.5, 1.0, 2.0, 5.0, and 10.0 MPa. Some results at $1 \mathrm{MPa}$ were compared with the results by Chervy et al. [5] in Table I. Our results approximately agree with values, which confirm the validity of our calculations. The differences between our result and Chervy's one in the electrical and thermal conductivities are considered to arise from differences in the order of approximation of the Chapman-Enskog method. We used the first-order approximation of the Chapman-Enskog method while Chervy did the third order. This difference produces errors in a high-temperature region in the present work. Another reason can be the differences collision integrals adopted.

\section{Gas-Flow Simulation MethodS}

The modified fluid-in-cell (FLIC) method developed for GCBs was adopted for numerical simulations [1]. The modified FLIC introduces nonconstructive grids in the FLIC, providing a kind of differential method. In this work, we considered the 


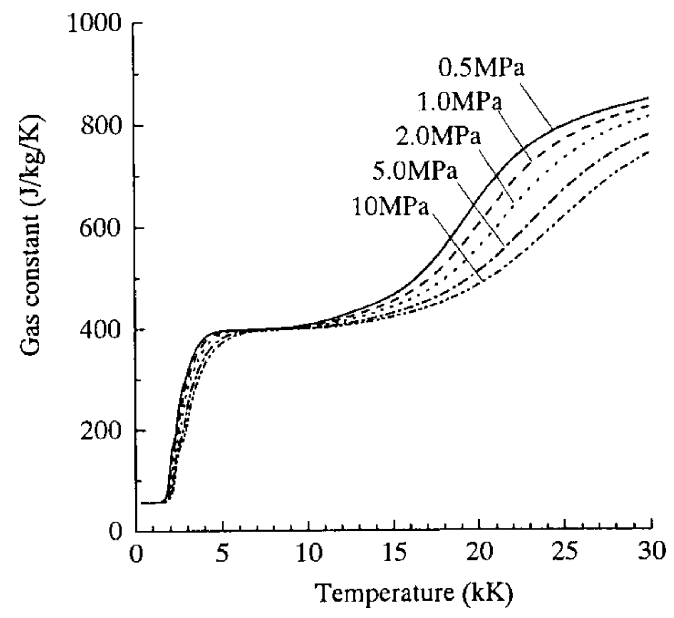

Fig. 2. Gas constants $R$.

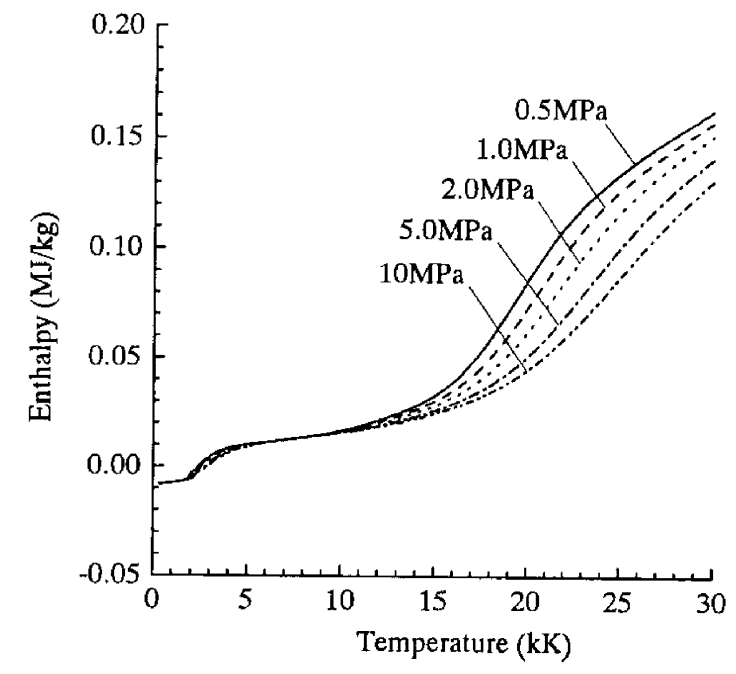

Fig. 3. Enthalpy $h$.

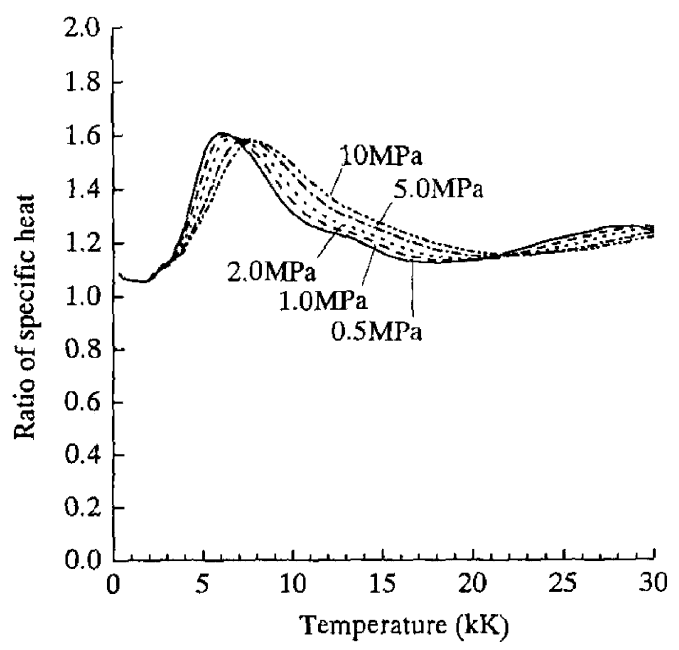

Fig. 4. Specific ratio $\gamma$.

mass of ablations of polytetrafluoroethylene (PTFE) from a nozzle and copper from electrodes. Also, we improved the arc model by calculating electrical conductivities and arc diameters. Moreover, thermal transport properties of $\mathrm{SF}_{6}$ gas of high pressures up to $10 \mathrm{MPa}$ and high temperatures up to 30000

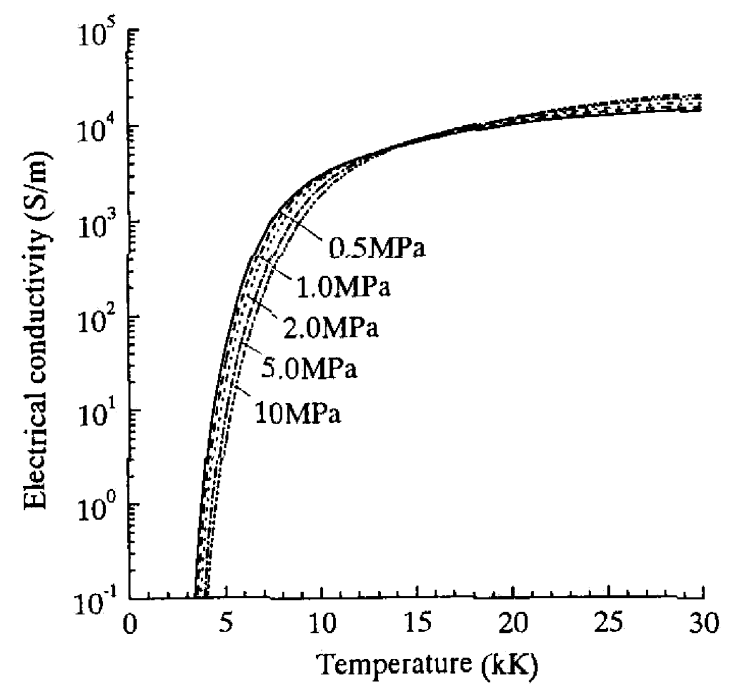

Fig. 5. Electrical conductivity $\sigma$.

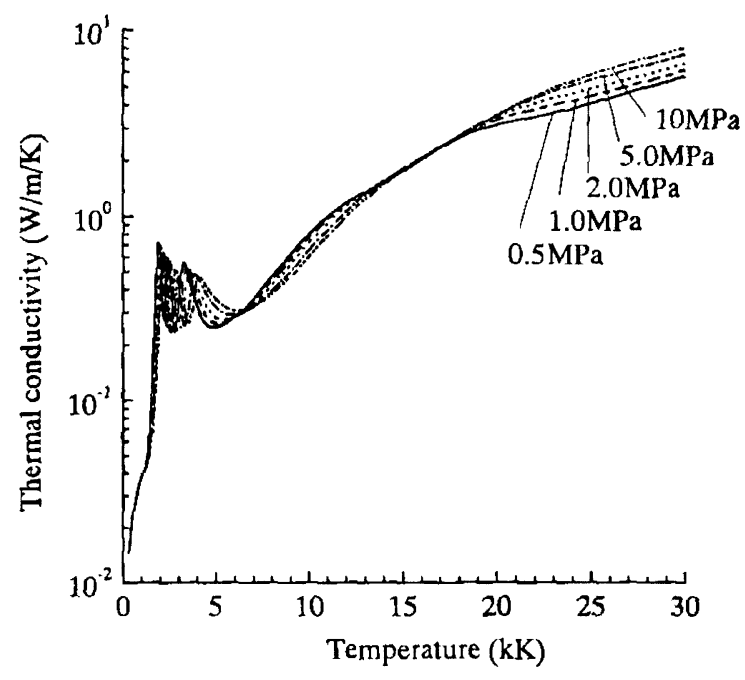

Fig. 6. Thermal conductivity.

$\mathrm{K}$ in Chapter II were used in the simulations. The simulation methods are represented in this chapter.

\section{A. Fundamental Equations}

Continuous equations and momentum equations for axis and radius directions and energy conservation equations are described as follows.

Continuous equations

$$
\begin{aligned}
& \frac{\partial \rho}{\partial \mathrm{t}}+\frac{\partial}{\partial \mathrm{x}}(\rho \mathrm{u})+\frac{1}{\mathrm{r}} \frac{\partial}{\partial \mathrm{r}}(\mathrm{r} \rho \mathrm{v})=0 \\
& \frac{\partial \rho_{\mathrm{p}}}{\partial \mathrm{t}}+\frac{\partial}{\partial \mathrm{x}}\left(\rho_{\mathrm{p}} \mathrm{u}\right)+\frac{1}{\mathrm{r}} \frac{\partial}{\partial \mathrm{r}}\left(\mathrm{r} \rho_{\mathrm{p}} \mathrm{v}\right)=0 \\
& \frac{\partial \rho_{\mathrm{c}}}{\partial \mathrm{t}}+\frac{\partial}{\partial \mathrm{x}}\left(\rho_{\mathrm{c}} \mathrm{u}\right)+\frac{1}{\mathrm{r}} \frac{\partial}{\partial \mathrm{r}}\left(\mathrm{r} \rho_{\mathrm{c}} \mathrm{v}\right)=0 .
\end{aligned}
$$

Momentum equation for axis direction

$$
\frac{\partial}{\partial \mathrm{t}}(\rho \mathrm{u})+\frac{\partial}{\partial \mathrm{x}}(\rho \mathrm{uu})+\frac{1}{\mathrm{r}} \frac{\partial}{\partial \mathrm{r}}(r \rho \mathrm{uv})=-\frac{\partial \mathrm{p}}{\partial \mathrm{x}} .
$$

Momentum equation for radius direction

$$
\frac{\partial}{\partial \mathrm{t}}(\rho \mathrm{v})+\frac{\partial}{\partial \mathrm{x}}(\rho \mathrm{vu})+\frac{1}{\mathrm{r}} \frac{\partial}{\partial \mathrm{r}}(r \rho \mathrm{vv})=-\frac{\partial \mathrm{p}}{\partial \mathrm{r}} .
$$


TABLE I

COMPARISON OF OUR Results AT 1.0 MPA With the RESUlts By ChERVy et al. [5]

\begin{tabular}{c|c|c|c|c|c|c|c|c}
\hline & \multicolumn{2}{|c|}{$\begin{array}{c}\text { Mass density } \\
\left(\mathrm{kg} / \mathrm{m}^{3}\right)\end{array}$} & \multicolumn{2}{c|}{$\begin{array}{c}\text { Enthalpy } \\
(\mathrm{MJ} / \mathrm{kg})\end{array}$} & \multicolumn{2}{c|}{$\begin{array}{c}\text { Electrical conductivity } \\
(\mathrm{S} / \mathrm{m})\end{array}$} & \multicolumn{2}{c}{$\begin{array}{c}\text { Thermal conductivity } \\
(\mathrm{W} / \mathrm{m} / \mathrm{K})\end{array}$} \\
\hline $\begin{array}{c}\text { Temperature } \\
(\mathrm{K})\end{array}$ & Our result & $\begin{array}{c}\text { Chervy et } \\
\text { al. }\end{array}$ & Our result & $\begin{array}{c}\text { Chervy et } \\
\text { al. }\end{array}$ & Our result & $\begin{array}{c}\text { Chervy et } \\
\text { al. }\end{array}$ & Our result & $\begin{array}{c}\text { Chervy et } \\
\text { al. }\end{array}$ \\
\hline 1000 & 17.799 & 17.6 & -7.4951 & -7.94 & $1.0267 \times 10^{-37}$ & - & 0.037316 & 0.0479 \\
3000 & 1.1419 & 1.16 & 3.5540 & 2.78 & 0.0063340 & 0.00655 & 0.24367 & 0.440 \\
10000 & 0.25031 & 0.247 & 16.162 & 15.8 & 2858.3 & 3420 & 0.76627 & 0.970 \\
30000 & 0.040572 & 0.04 & 157.29 & 158 & 15517 & 21400 & 6.0760 & 8.73 \\
\hline
\end{tabular}

Energy conservation equations

$$
\begin{aligned}
\frac{\partial}{\partial \mathrm{t}}( & \rho E)+\frac{\partial}{\partial x}(\rho E u)+\frac{1}{r} \frac{\partial}{\partial r}(r \rho E v) \\
= & -\frac{\partial}{\partial x}(p u)-\frac{1}{r} \frac{\partial}{\partial r}(r p v)-\kappa \frac{\partial}{\partial x}\left[\frac{\partial T}{\partial x}\right]-\kappa \frac{1}{r} \frac{\partial}{\partial r}\left[r \frac{\partial T}{\partial r}\right] \\
& +q_{\mathrm{arc}}-q_{\mathrm{rad}}-\rho_{p} E_{\mathrm{pab}}-\rho_{c} E_{\mathrm{cab}} \\
E & =\frac{p}{(\gamma-1) \rho}+\frac{1}{2}\left(u^{2}+v^{2}\right)
\end{aligned}
$$

where $E$ is the energy per mass unit; $E_{\text {pab }}$ is ablation energy of PTFE per mass and time unit; $E_{\text {cab }}$ is ablation energy of copper per mass and time unit; $p$ is pressure; $q_{\mathrm{arc}}$ is the inputted thermal energy of an arc per-unit volume; $q_{\mathrm{rad}}$ is the thermal radiation from an arc; $r$ is the radius coordinate value; $T$ is temperature; $t$ is time; $u$ is axial velocity; $v$ is radius velocity; $x$ is axial coordinate; $\gamma$ is specific heat ratio; $\kappa$ is the thermal conductivity ratio; and $\rho, \rho_{p}$, and $\rho_{c}$ are densities of $\mathrm{SF}_{6}$ gas, PTFE, and copper, respectively.

Equation (16) represents the mass balance of the mixture gas of $\mathrm{SF}_{6}$, PTFE, and copper. Similarly, (17) and (18) represent the mass balances of PTFE and copper, respectively.

Thermodynamic and transport properties of $\mathrm{SF}_{6}$ gas up to a pressure of $10 \mathrm{MPa}$ and a temperature of $30000 \mathrm{~K}$, which were obtained in Chapter 2, were adopted. The program had the values in tables and derived corresponding values at each mesh.

\section{B. Modeling of the Arcs}

Arc energy $q_{\text {arc }}$ for each mesh in arcing area is given by multiplying arc current and average arc voltage, which was specified by referring to experimental measured values.

Considering an arc as a gray body, the thermal radiation of the arc $q_{\mathrm{rad}}$ is given by (23)

$$
q_{\mathrm{rad}}=\varepsilon \sigma_{s}\left(T_{\mathrm{arc}}^{4}-T_{\mathrm{amb}}^{4}\right) S
$$

where $T_{\mathrm{arc}}$ is the arc temperature, $T_{\mathrm{amb}}$ is the temperature of surrounding area, $S$ is the surface area, $\varepsilon$ is the radiation ratio, $\sigma_{s}$ is the Stephan-Boltzmann constant $\left(5.6687 \times 10^{-8} \mathrm{~W} / \mathrm{m}^{2}\right.$ $\left.\mathrm{K}^{4}\right) . T_{\mathrm{amb}}$ corresponds to the temperature of the nozzle wall surface because the arc burns within a nozzle.

Copper of electrodes and PTFE of the nozzle are vaporized and sublimated by the arc, which reduces arc energy and cools the arc. The cooling effect was also considered in our simulations. Moreover, arc energy is sublimated by the dissociation of PTFE. Table II shows values of ablation energies. The total amounts of ablated materials were estimated from experimental results.
TABLE II

ABLATION ENERGIES OF PTFE AND COPPER

\begin{tabular}{c|c|c|c|c}
\hline & $\begin{array}{c}\text { Evaporation } \\
\text { temperature } \\
(\mathrm{K})\end{array}$ & $\begin{array}{c}\text { Evaporation } \\
\text { energy } \\
(\mathrm{J} / \mathrm{kg})\end{array}$ & $\begin{array}{c}\text { Dissociation } \\
\text { temperature } \\
(\mathrm{K})\end{array}$ & $\begin{array}{c}\text { Dissociation } \\
\text { energy } \\
(\mathrm{J} / \mathrm{kg})\end{array}$ \\
\hline PTFE & 600 & $5.73 \times 10^{4}$ & 3400 & $1.19 \times 10^{7}$ \\
\hline Copper & 1360 & $4.80 \times 10^{6}$ & $\mathrm{~N} / \mathrm{A}$ & $\mathrm{N} / \mathrm{A}$ \\
\hline
\end{tabular}

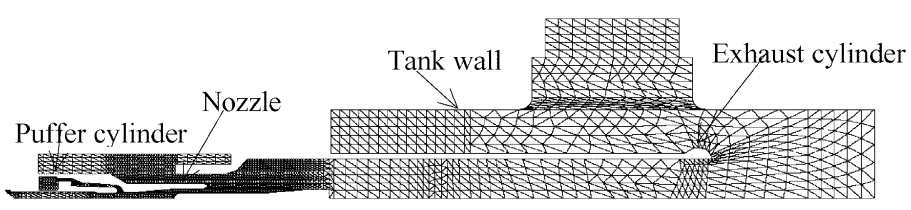

Fig. 7. Grids for simulation (example for MMM).

\section{Simulation Method of Moving Parts in GCBs}

Fig. 7 shows an example of grids used for the simulation by the modified FLIC, which introduces triangular grids. The simulation was carried out for a large area in a dead-tank-type GCB including tank walls. The chamber simulated was the Hybrid-Puffer ${ }^{\mathrm{TM}}$ type [13], [14]. In this type of chamber, the arcing area and puffer chamber are connected through holes in the wall of an operating rod with contacts in the closed position. At the early period of the opening operation of the contacts, heat energy generated by arcs flows into the puffer chamber through the hole. As the contacts open, the hole moves out the puffer chamber and the hot gas from the arc area flows out to the free gas area in the GCB.

In reality, a movable part, including a puffer cylinder, movable arcing contacts, movable main contacts, and nozzles, moves with the operating rod, and compresses the puffer volume, which creates a gas flow during a current interruption. In our conventional method, stationary contacts and puffer pistons were moved because it was relatively easy to simulate [stationary parts moving method (SMM)]. Although the real operation is continuous, it is very hard to simulate. It is true that some researchers have been trying and achieved excellent simulations by adopting high quality and complicated algorithms [15]. However, attempting to develop engineering tools, which require only reasonable time durations for the simulations, we have used some mesh data for different positions between close and open positions. As the simulation progresses, data are transferred from the previous position to the next position.

Fig. 8 shows movements of configurations and the transfer of data in SMM. New meshes were created at the front of a stationary contact, and meshes in front of a puffer piston were deleted. 


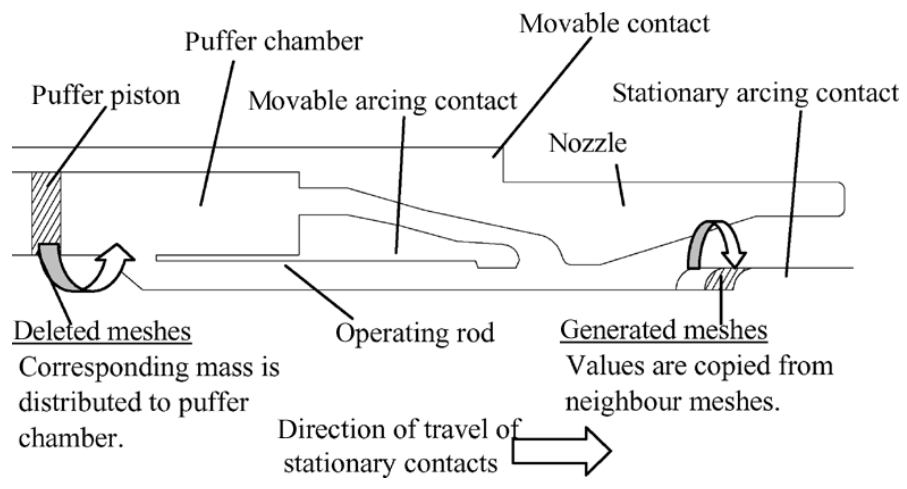

Fig. 8. Data transport in SMM.

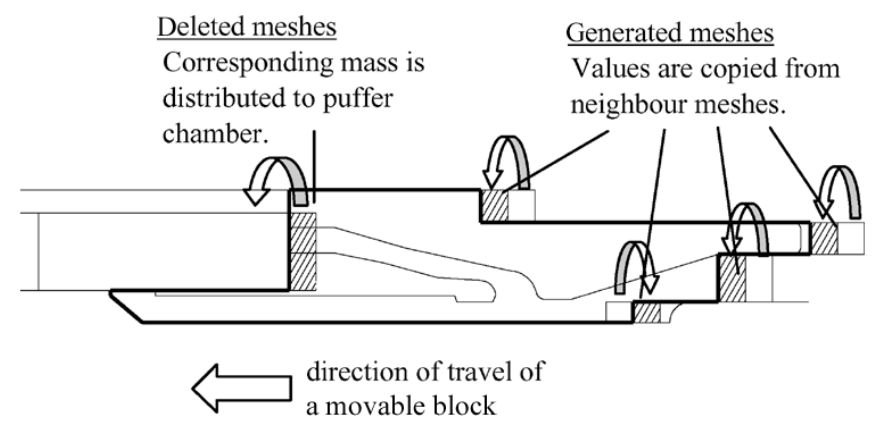

Fig. 9. Data transport in MMM.

On the other hand, Fig. 9 shows a method in which an operational rod, a movable arcing contact, a movable main contact, and a nozzle move in the same way as real GCBs [movable parts moving method (MMM)]. As shown by thick lines in the figure, blocks with horizontal or vertical lines consist of parts to be deleted or created and are built to be moved.

In the simulation, physical values of gas properties were obtained by interpolating values of calculated results shown in Chapter II.

\section{Simulation Results}

\section{A. Pressure in Puffer Chamber}

Fig. 10 shows simulation results of pressure at a puffer chamber with measured values. The measured values were obtained using a pressure sensor, which was installed at the center of the puffer piston in the radius direction. Fig. 10 also includes a simulation result by a conventional simulation method, which had used $\mathrm{SMM}$ and $\mathrm{SF}_{6}$ gas properties up to $1.62 \mathrm{MPa}$. SMM with the new gas properties resulted in better values which did not have too high a pressure rise of around 0.9 p.u. However, SMM indicated higher values than the measured values. MMM successfully agreed with the measured values.

Fig. 11(a) and (b) shows pressure distributions in the puffer chamber at a stroke of 0.9 p.u. for SMM and MMM, respectively. The distribution for SMM has partially high pressure while MMM has a uniform distribution.

\section{B. Gas Flow in Exhaust Cylinder}

Another important purpose of the gas-flow simulation in GCBs is to investigate dielectric characteristics between

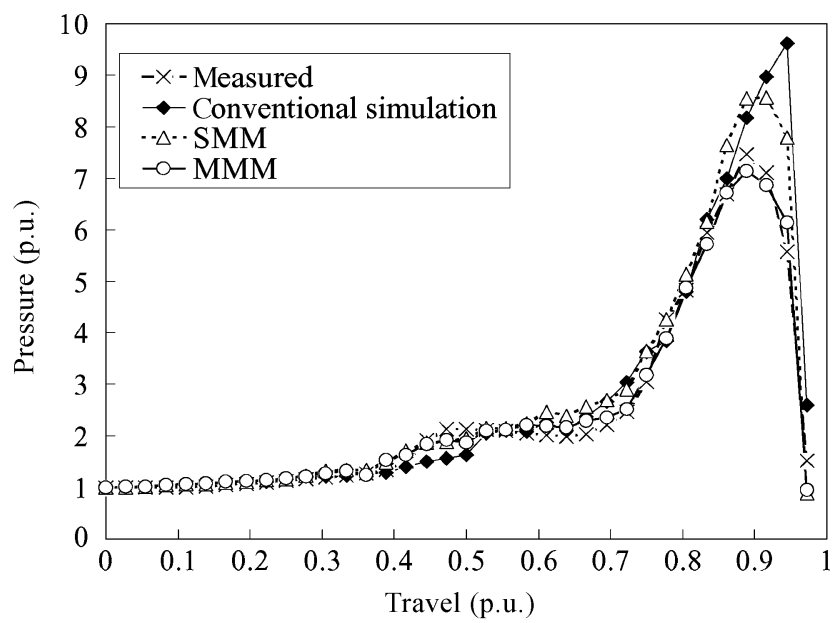

Fig. 10. Pressure in puffer chamber.

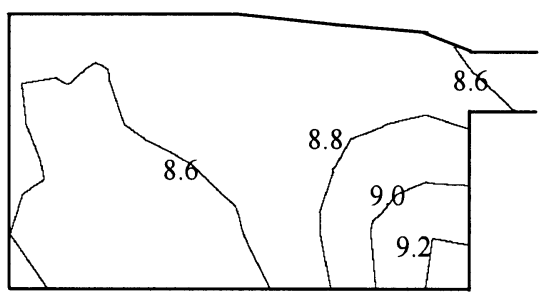

(a)

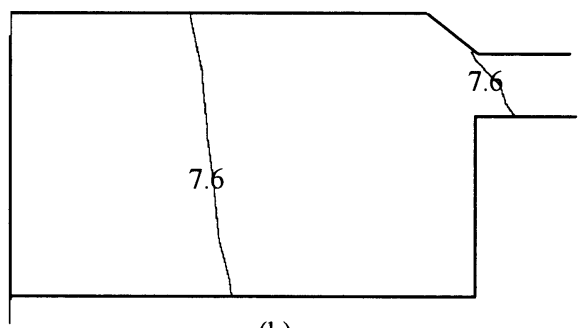

(b)

Fig. 11. Pressure distribution in puffer chamber. (a) SMM. (b) MMM. (Values on contours represent pressure in per unit.)

chambers and enclosing tanks. Our FLIC has simulated a hot gas flow exhausting from the chamber toward the tank wall [1], [2]. What we want to know from such simulations are the dielectric strengths after current zero. Transient recovery voltages (TRVs), which are higher than operating voltage in the system, are applied to GCBs within several hundreds of microseconds after current zero, then the operating voltage (is applied) continuously. To evaluate dielectric strength, gas density and temperature are significant parameters along with electric field strength [16]-[18]. Fig. 12 compares gas density at the top of an exhaust cylinder, which is a critical point for dielectric performance [16], [17] in a GCB, simulated by SMM and MMM. In these simulations, a high current arc of $50 \mathrm{~Hz}$ is ignited at $0 \mathrm{~ms}$ on the time axis and extinguished at $20 \mathrm{~ms}$.

Densities simulated by both SMM and MMM rise from a basic level up to $13 \%$. Then, the density of SMM starts to drop at $19 \mathrm{~ms}$ and decreases to $75 \%$ of a basic level. On the other hand, the density of MMM starts to drop $1 \mathrm{~ms}$ later than SMM and decreases to $56 \%$. 


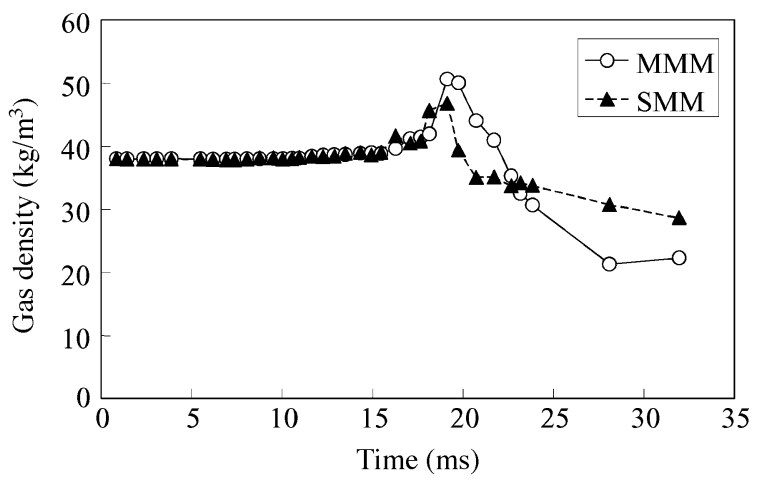

Fig. 12. Density variation at the end of an exhaust cylinder.

\section{INTERPRETATIONS}

\section{A. Pressure in Puffer Chamber}

It is difficult to measure the state of the area between two arcing contacts that strongly affect interruption performance. Therefore, we would like to discuss puffer pressure, which can be measured easily with high precision.

The effect of considering detailed $\mathrm{SF}_{6}$ gas properties can be stated for a reduction of pressure around 0.9 p.u. of stroke as shown in Fig. 10. The effect cannot be simply explained because the simulation treats nonlinear data with iterations to obtain physical constants at each mesh. However, it can find that the pressure in the puffer chamber decreased because pressures at the arc area decreased due to a lower gas constant by considering gas properties at higher pressures.

Second, we discuss differences between SMM and MMM. Adding to large differences around stroke 0.9 p.u., as stated above, the different situation could be observed with a shorter stroke. Fig. 13(a) and (b) are density distributions in the puffer area of SMM and MMM, respectively. In Fig. 13(a) of SMM, the density around the hole in the puffer is locally low. This is because the hole stays at the same place in the puffer. On the other hand, the density in Fig. 13(b) of MMM is relatively uniform. This is because the hole moves toward the opening direction along the puffer, which prevents the hot gas flow from staying in the same place. Therefore, these results would suggest that MMM would be the better method to simulate the Hybrid-Puffer ${ }^{\mathrm{TM}}$ type chambers precisely.

\section{B. Gas Flow in Exhaust Cylinder}

The reason why densities rise around $17 \mathrm{~ms}$ in Fig. 12 is that hot gas flowing in the exhaust cylinder pushes and compresses the cold gas forward. This phenomenon has also measured experimentally in GCBs [19], which suggested that our simulations gave the proper trends.

Differences of a delay in the density drop and density level after the drop between SMM and MMM can be explained by higher pressure in the puffer chamber of SMM. As shown in Fig. 10, the pressure in the puffer chamber simulated by SMM is higher than that of MMM, which might create a strong gas flow toward the exhaust cylinder. Therefore, hot gas in SMM reaches the top of the exhaust cylinder faster than that in MMM. Moreover, the hot gas travelling in the exhaust cylinder moves

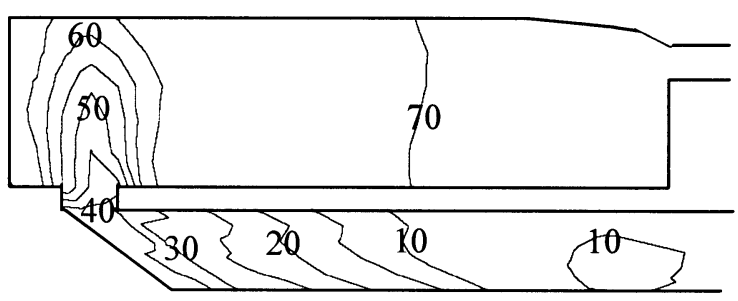

(a)

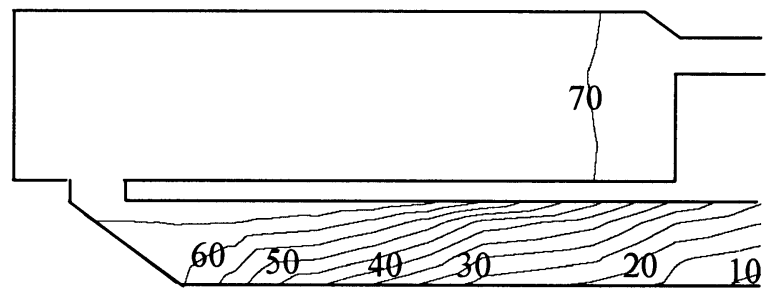

(b)

Fig. 13. Density distribution in puffer chamber. (a) SMM. (b) MMM. [Values on contours represent density $\left(\mathrm{kg} / \mathrm{m}^{3}\right)$ ]

to form one large area, which is mixed with cool gas forward and backward. When the gas is generated at a higher pressure, as seen in SMM, the hot gas can mix with the cool gas very well. Therefore, our SMM resulted in a higher density at the top of the exhaust cylinder than MMM.

The facts stated in this section also suggest that MMM is a better solution than SMM to simulate dielectric strength against dead-tanks in the Hybrid-Puffer ${ }^{\mathrm{TM}}$ type chambers, and the results should be much closer to real phenomena.

\section{CONCLUSION}

This paper presented the improved FLIC of CFD for the Hybrid-Puffer ${ }^{\mathrm{TM}}$ type $\mathrm{GCB}$ chamber on the following points.

a) Considering the thermodynamic and transport properties of $\mathrm{SF}_{6}$ gas: gas constant, enthalpy, ratio of specific heat, electrical conductivity, and thermal conductivity have been obtained by solving equations of dissociation and ionization reactions for 23 kinds of particles which include molecules, atoms, ions, and electrons. Particle composition in $\mathrm{SF}_{6}$ gas of temperature 300-30000 K was obtained up to $10 \mathrm{MPa}$ of pressure. The simulation results by the FLIC taking into account these values gave lower puffer pressures which agree with the measured values.

b) Simulating movement of movable parts: movable parts were simulated as a moving part. The new method, MMM, resulted in a lower pressure in the puffer chamber, which agrees with the experimentally measured value ands is much better than in the conventional SMM. The difference on puffer pressure also resulted in a later drop of density at the top of exhaust cylinder and a lower density in MMM, which must be much closer to real phenomena. The differences should be concerned when the Hybrid-Puffer ${ }^{\mathrm{TM}}$ type chamber are simulated precisely.

The simulation methods described in this paper were adapted to develop new GCBs of 145 [20] and $245 \mathrm{kV}$ [14] at TMT\&D Corporation. 


\section{ACKNOWLEDGMENT}

The authors would like to thank the late Prof. T. Sakuta of Kanazawa University for his cooperation and instruction in carrying out the simulations and publishing of this paper.

\section{REFERENCES}

[1] M. Okamoto, M. Ishikawa, K. Suzuki, and H. Ikeda, "Computer simulation of phenomena associated with hot gas in puffer-type gas circuit breaker," IEEE Trans. Power Del., vol. 6, no. 2, pp. 833-839, Apr. 1991.

[2] T. Mori, H. Ohashi, H. Mizoguchi, and K. Suzuki, "Investigation of technology of developing large capacity and compact size GCB," IEEE Trans. Power Del., vol. 12, no. 1, pp. 747-753, Feb. 1997.

[3] L. S. Frost and R. W. Liebermann, "Composition and transport properties of $\mathrm{SF}_{6}$ and their use in a simplified enthalpy flow arc model," Proc. IEEE, vol. 59, no. 4, pp. 474-485, Apr. 1971.

[4] A. Gleizes, M. Razafinimanana, and S. Vacquié, "Equilibrium Composition Thermodynamic Properties and Transport Coefficients of $\mathrm{SF}_{6}-\mathrm{N}_{2}$ Mixtures,” Rep., Internal Rep. 40 277-85-1 CNRS, Feb. 1985. EDF arc Electrique.

[5] B. Chervy, A. Gleizes, and M. Razafinimanana, "Thermodynamic properties and transport coefficients in $\mathrm{SF}_{6}-\mathrm{Cu}$ mixtures at temperatures of 300-30000 K and pressures of 0.1-1 MPa,"J. Phys. D, Appl. Phys., vol. 27, pp. 1193-1206, 1994.

[6] J. Y. Trépanier, M. Reggio, H. Zhang, and R. Camarero, "A finite-volume method for the Euler equations on arbitrary Lagrangian-Eulerian grids," Comput. Fluids, vol. 20, no. 4, pp. 399-409, 1991.

[7] P. Chévrier, M. Barrault, C. Fiéver, J. Maftoul, and J. M. Frémillon, "Industrial applications of high-, medium- and low-voltage arc modeling," J. Phys. D, Appl. Phys., vol. 30, pp. 1346-1355, 1997.

[8] M. Claessens, K. Möller, and H. G. Thiel, "A computational fluid dynamics simulation of high- and low-current arcs in self-blast circuit breakers," J. Phys. D, Appl. Phys., vol. 30, pp. 1899-1907, 1997.

[9] S. Kwan, M. S. Christodoulou, W. Hall, and M. T. C. Fang, "The theoretical modeling of puffer circuit breakers," in Proc. 11th Int. Conf. Gas Discharges Their Applications, vol. 1, Sep. 1995, pp. 374-377.

[10] Y. Tanaka, K. C. Paul, and T. Sakuta, "Thermodynamic and transport properties of $\mathrm{N}_{2} / \mathrm{O}_{2}$ mixtures at different admixture ratios," Trans. Inst. Elect. Eng. Jpn., vol. 120-B, pp. 24-30, 2000.

[11] K. C. Paul, T. Sakuta, and T. Takashima, "Transport and thermodynamic properties of $\mathrm{SF}_{6}$ gas contaminated by PTFE reinforced with A12O3 ad BN particles," IEEE Trans. Plasma Sci., vol. 25, no. 4, pp. 786-798, Aug. 1997.

[12] J. M. Yos, Transport Properties of Nitrogen, Hydrogen, Oxygen, and Air to $30000 \mathrm{~K}$, Massachusetts: Research and Advanced Development Division AVCO Corporation, 1967, Amendments to AVCO RAD-TM-63-7.

[13] S. Yanabu, H. Mizoguchi, and M. Toyoda, "Development of novel hybrid interrupting chamber for gas circuit breaker utilizing self-pressure-rise phenomena by arc,' IEEE Trans. Power Del., vol. 4, no. 1, pp. 355-361, Jan. 1989.

[14] T. Mori, H. Mizoguchi, N. Kato, and M. Toyoda, "Investigation of two types of interrupting chamber with low drive energy and development of 245-kV GCB," IEEE Trans. Power Del., vol. 10, no. 1, pp. 158-167, Jan. 2004.

[15] S. D. Eby and J. Y. Trépanier, "Computation of the radiative transfer in $\mathrm{SF}_{6}$ circuit-breaker arcs using the $\mathrm{P}-1$ model of radiation," in Proc. 12th Int. Conf. Gas Discharges Their Applications, vol. 2, Sep. 1997, pp. 570-573.

[16] T. Uchii, S. Nishiwaki, and S. Boggs, "Effects of hot $\mathrm{SF}_{6}$ on post-arc circuit breaker design," IEEE Trans. Power Del., vol. 10, no. 1, pp. 124-130, Jan. 2004.

[17] T. Uchii, T. Nakamoto, S. Nishiwaki, M. Toyoda, and S. A. Boggs, "Optimization of dead tank gas circuit breaker design based on quantification of hot gas flow and dielectric properties," IEEE Trans. Power Del., vol. 10, no. 1, pp. 181-184, Jan. 2004.

[18] G. J. Cliteur, Y. Hayashi, E. Haginomori, and K. Suzuki, "Calculation of the uniform breakdown field strength of $\mathrm{SF}_{6}$ gas," IEEE Trans. Dielect. Elect. Insul., vol. 5, no. 6, pp. 843-849, Dec. 1998.

[19] Y. Hayashi, G. J. Cliteur, M. Ishikawa, and K. Suzuki, "Diffusion process of hot gas flow during the short circuit current interruption of $\mathrm{SF}_{6}$ gas circuit breaker," in Proc. 11th Int. Conf. Gas Discharges Their Applications, vol. 1, Sep. 1995, pp. 390-393.
[20] M. Toyoda, H. Mizoguchi, T. Uchii, T. Yokota, T. Ueda, and S. Ohyama, "Review of GCB and its improved interrupting chamber," in Proc. Beijing Int. Conf. Power Transmission Distribution Technology, 2001, pp. 2001-2011.

Tadashi Mori (M'96) was born in Aichi Prefecture, Japan, on June 14, 1966. He received the B.S. and M.S. degrees in electrical engineering from Nagoya University, Nagoya, Japan, in 1989 and 1991, respectively.

Currently, he is a Deputy Manager of the T\&D Research and Development Center, TMT\&D Corporation, Kawasaki, Japan, a company formed when the T\&D operations of Toshiba, Kawasaki, and Mitsubishi Electric, Amagasaki, Japan, were combined in 2002. In 1991, he was with Toshiba Corporation, Kawasaki, engaged in the development of gas-insulated switchgears and the study of interruption phenomena.

Mr. Mori is a member of the Institute of Electrical Engineering of Japan. He was an Honorary Research Associate at the University of Liverpool, Liverpool, U.K., from 2000 to 2002 .

Hiromichi Kawano (M'04) was born in Oita Prefecture, Japan, on March 7, 1961. He received the B.S. and M.S. degrees in electrical engineering from Kyoto University, Kyoto, Japan, in 1983 and 1985, respectively.

Currently, he is a Manager of the T\&D Research and Development Center, TMT\&D Corporation, Kawasaki, Japan, a company formed when the T\&D operations of Toshiba, Kawasaki, and Mitsubishi Electric, Amagasaki, Japan, were combined in 2002. In 1985, he was with Toshiba Corporation, Kawasaki, where he was engaged in the development and design of gas-insulated switchgears and the study of interruption phenomena. He was an Academic Visitor at the University of Oxford, Oxford, U.K., from 1990 to 1992.

Mr. Kawano is a member of the Institute of Electrical Engineering of Japan.

Katsuharu Iwamoto was born in Yamaguchi, Japan, on September 15, 1948. He received the B.S., M.S., and Ph.D. degrees in mechanical engieering from Kyushu University, Fukuoka, Japan, in 1971, 1973, and 1996, respectively.

Currently, he is a Senior Specialist of the T\&D Research and Development Center, TMT\&D Corporation, Kawasaki, Japan, a company formed when the T\&D operations of Toshiba, Kawasaki, and Mitsubishi Electric, Amagasaki, Japan, were combined in 2002. In 1973, he was with Toshiba Corporation, Kawasaki, engaged in the development of a steam turbine. Then he worked on gas-flow analysis and measurements in gas circuit breakers (GCBs).

Dr. Iwamoto is a member of the Japan Society of Mechanical Engineers, the Japan Society of Applied Physics, and the Optical Society of America.

Yasunori Tanaka was born in Japan on November 19, 1970. He received the B.S., M.S., and Ph.D. degrees in electrical engineering from Nagoya University, Nagoya, Japan, in 1993, 1995, and 1998, respectively.

He was a Research Associate and then was an Associate Professor in the Department of Electrical and Electronic Engineering, Kanazawa University, Kanazawa, Japan, where he has been since 1998. His research interests include the arc interruption phenomena and thermal plasma applications.

Dr. Tanaka is a member of the Institute of Electrical Engineering of Japan.

Eiji Kaneko (M'79) was born in Aichi Prefecture, Japan, on September 16, 1952. He received the B.S., M.S., and Ph.D. degrees in electrical engineering from Nagoya University, Nagoya, Japan, in 1975, 1977, and 1989, respectively.

Currently, he is Associate Professor with the Faculty of Engineering of University of the Ryukyus, Okinawa, Japan. In 1977, he joined the High Power Laboratory of Toshiba Corporation, Kawasaki, Japan, and was engaged in the research and development on high-power circuit breakers (CBs).

Dr. Kaneko is a member of the Institute of Electrical Engineering of Japan and the Japan Society of Applied Physics. 